NBER WORKING PAPER SERIES

STAGGERED WAGE SETTING WITHOUT MONEY

ILLUSION: VARIATIONS ON A THEME OF TAYLOR

Willem H. Buiter

Ian Jewitt

Working Paper No. $\underline{54}$

NATIONAL BUREAU OF ECONOMIC RESEARCH

1050 Massachusetts Avenue

Cambridge MA 02138

September 1980

The research reported here is part of the NBER's research program in International Studies. Any opinions expressed are those of the authors and not those of the National Bureau of Economic Research. 


\section{Staggered Wage Setting Without Money Illusion: Variations on a Theme of Taylor}

\section{$\underline{\text { ABSTRACT }}$}

Taylor's model of staggered wage setting is reformulated in terms of anticipated relative real wages rather than relative money wages. The relative real wage (RRW) model exhibits more nominal inertia than the relative money wage (RMW) model in the following sense. With $\mathrm{N}$-period contracts the $\mathrm{RRW}$ model yields a $2 \mathrm{~N}-2$ order stochastic difference equation in the contract wage while Taylor's RMW model yields an $\mathrm{N}-1$ equation. Unlike the RMW model the lag coefficients need not all have a common sign. It is also shown that Taylor's money wage model with relative wage effects is observationally equivalent to a real wage model without relative wage effects. Taylor's conclusion that rational expectations combined with nominal inertia (due e.g., to overlapping, staggered, non-contingent money wage contracts) leave scope for known contingent monetary policy rules to influence such real variables as the variance of real output is not affected.

Willem H. Buiter

Ian Jewitt

Department of Economics University of Bristol 40 Berkeley Square Bristol BS81HY ENGLAND

Telephone: 0272-24161 


\section{INTRODUCTION}

In a number of influential recent papers Taylor $(1979 a, b ; 1980 a, b)$ has analysed the behaviour of an economy characterized by staggered overlapping wage contracts and rational expectations. His model has "Keynesian" features. In particular, the distribution function of real output is not invariant under alternative deterministic (and known) monetary policy rules. A sufficient reason for this is the inertia in the money wage process induced by the staggered contracts. One of the aims of our paper is to demonstrate that this is sufficient by removing what may be considered a form of money illusion from Taylor's model. In that model, wage bargainers are influenced by relative money wages rather than relative real wages. Money wage contracts are negotiated without reference to past, current and expected future prices. Our paper modifies Taylor's model to render it immune to the money illusion criticisn. The suggested modification does not eliminate the Keynesian qualities of the model. It does, however, have interesting implications for the empirical estimation of models with staggered wage contracts (see especially Taylor, 1980b).

Section 2 presents our general N-period overlapping staggered real wage model or relative real wage model (RRW) and contrasts it with Taylor's relative money wage model (RMW). Section 3 contains some explicit numerical solutions of the RRW model which are then compared with the solutions of the corresponding RMW models. One can distinguish three influences on the contract wage. These are the average price level expected to prevail over the contract, demand effects and the response of bargainers to relative (real or nominal) wages. Taylor's model contains the demand effect and the relative nominal wage effect. Section 4 analyses staggered real and money wage contracts without relative wage effects. 
One conclusion is that Taylor's RMW model is observationally equivalent to a staggered real wage model without relative wage effects. Section 5 considers some empirical implications of the RRW model.

2. A comparison of the general solution of Taylor's relative money wage model and the relative real wage model

Taylor's RMW model is presented in equations (1) - (4)

$$
\begin{aligned}
& x_{t}=\sum_{s=1}^{N-1} d-s x_{t-s}+\sum_{s=1}^{N-1} d_{s} \hat{x}_{t-1 \mid t+1}+\sum_{\frac{\gamma}{N}}^{N-1} \hat{y}_{t-1} \mid t+s+\varepsilon_{t} ; \gamma>0 \\
& y_{t}+p_{t}=m_{t}+v_{t} \\
& p_{t}=\frac{1}{N} \sum_{i=0}^{N-1} x_{t-i} \\
& m_{t}=(1-\beta) p_{t}
\end{aligned}
$$

The logarithm of the money contract wage negotiated in period $t$ is denoted by $x_{t}$. Wage contracts last $\mathrm{N}$ periods. A constant fraction $\frac{1}{\mathrm{~N}}$ of all firms and all workers settle in any given period. The contract wage is constant over the duration of the contract. We shall assume in this section, along with Taylor (1980a), that the weights on future and past contract wages are symmetric, linearly declining in $s$ and sum to unity, i.e.

$$
d_{s}=d_{-s}=b_{s}=[N(N-1)]^{-1}(N-s) \quad s=1, \ldots, N-1
$$


market, since the level of full employment output is assumed to be constant throughout. $p_{t}$ and $m_{t}$ are the logs of the price level and tine nominal money stock respectively. The terms $\varepsilon_{t}$ and $v_{t}$ are white noise disturbances with zero means and a constant contemporaneous variance-covariance matrix. For any variable $z$, say, $z_{t-1} \mid t+s$ is the mathematical expectation of $z_{t+s}$ conditional on the information available in period $t-1$. Equation (2) is a very simple aggregate demand equation=! Equation (3) specifies the current price level, $\mathrm{p}_{t}$ ' as a proportional mark-up on the average of the contract wages in effect during period t. Equation (4) is an instantaneous monetary policy response function. $2 /$

In Taylor's own words, the two key assumptions of the RMW model are "(1) wage contracts are staggered, that is, not all wage decisions in the economy are made at the same time, and (2) when making wage decisions, firms (and unions) look at the wage rates which are set at other firms and which will be in effect during their contract period." [Taylor, (1980a, p. 2)].

It is important to note that the second assumption refers to current multiperiod money wage contract decisions that are made with reference to all other money wage contracts what will be in effect during the periods covered by the current contract. While currently contracting firms and unions may well be interested in their wages relative to those of firms and unions contracting at earlier and later dates, rational behaviour would seem to require that the relative real values of these contracts and not the relative money wages per se should be the proper focus of concern. It can therefore be argued that Taylor's RMW model does not isolate the implications of having multi-period non-contingent (i.e. open-loop) money wage contracts $3 /$ from those of having a form of money illusion. 
The RRW model modifies the wage setting process in the following way. The contract money wage of firms and unions settling in period $t, x_{t}$, is set to achieve a given expected (target) real wage over the duration of the contract. This expected target real wage depends on expected average excess demand during the contract interval and on the real wages that are expected to be achieved by other firms and unions whose contracts overlap with the period $t$ contract. With $\mathrm{N}$-period contracts, the current contract money vage is therefore directly dependent on current expectations of the price level during the current and the following $\mathrm{N}-1$ periods. Indirectly, because of the dependence of the current contract wage on the expected real value of the contract wages with which it overlaps, the current contract wage will depend on current expectations of the price level during the next $2 \mathrm{~N}-2$ periods.

In general there are three kinds of arguments in the structural equation for the current contract wage. First, the price expectation effect, which reflects the influence of the average price level expected over the life of the contract. This effect is absent in the RMW model. Second, the relative wage effect, which can be in terms of either real or money wages. Finally, the demand effect which represents the influence of the average level of excess demand in the labour market expected over the life of the contract.

Formally, the RRW model retains equations (2) - (5) but replaces (1) by

$$
\begin{aligned}
x_{t}-\frac{1}{N} \sum_{s=0}^{N-1} \hat{p}_{t-1 \mid t+s} & =\sum_{s=1}^{N-1} d_{-s}\left(x_{t-s}-\frac{1}{N} \sum_{j=0}^{N-1} \hat{p}_{t-1 \mid t-s+j}\right) \\
& +\sum_{s=1}^{N-1} d_{s}\left(\hat{x}_{t-1 \mid t+s}-\left.\frac{1}{N} \sum_{j=0}^{N-1} \hat{p}_{t-1}\right|_{t+s+j}\right) \\
& +\left.\frac{\gamma}{N} \sum_{s=0}^{N-1} \hat{y}_{t-1}\right|_{t+s}+\varepsilon_{t}
\end{aligned}
$$


Note that in (6) we specify the expected real contract wage represented by the money contract wage that is expected to be negotiated in period $t+s$ by $\hat{x}_{t-1 \mid t+s}-\frac{1}{\bar{N}} \sum_{j=0}^{N-1} \hat{P}_{t-1 \mid t+s+j}$. This is the expectation of the average rea 1 wage negotiated by firms and unions contracting in period $t+s$ over the entire duration of that contract, i.e. from period $t+s$ to period $t+s+N-1$. One interpretation of the Taylor RMN model is that firms and unions negotiate not on the basis of the actual and expected values of contracts established by other firms and unions but on the basis only of those real wages earned by other workers whilst the currently negotiated contract is in force. According to this interpretation, (6) should be replaced by

$$
\begin{aligned}
x_{t}-\frac{1}{N} \Sigma_{s=0}^{N-1} \hat{p}_{t-1 \mid t+s}= & \Sigma_{s=1}^{N-1} d_{-s}\left(x_{t-s}-\frac{1}{N-s} \Sigma_{j=s}^{N-1} \hat{p}_{t-1 \mid t-s+j}\right) \\
& +\sum_{s=1}^{N-1} d_{s}\left(\hat{x}_{t-I t+s} \frac{1}{N-s} \Sigma_{j=0}^{N-1-s} \hat{p}_{t-1 \mid t+s+j}\right) \\
& +\frac{Y_{N}^{N} \Sigma_{s=0}^{N-1}}{\hat{y}_{t-1 \mid t+s}}+\varepsilon_{t} .
\end{aligned}
$$

The two possible interpretations of relative real wages are illustrated in table 1. In the model of equation. (6) firms and unions contracting in period $t$ interpret the real value of the contract formed in period $t+2$ as $\hat{\mathbf{x}}_{t-1 \mid t+2}-\frac{1}{3}\left(\hat{p}_{t-1} ; t+2+\hat{p}_{t-1 \mid t+3}+\hat{p}_{t-1 \mid t+4}\right)$. The model of $(7)$, on the other hand would substitute 
TABLE 1

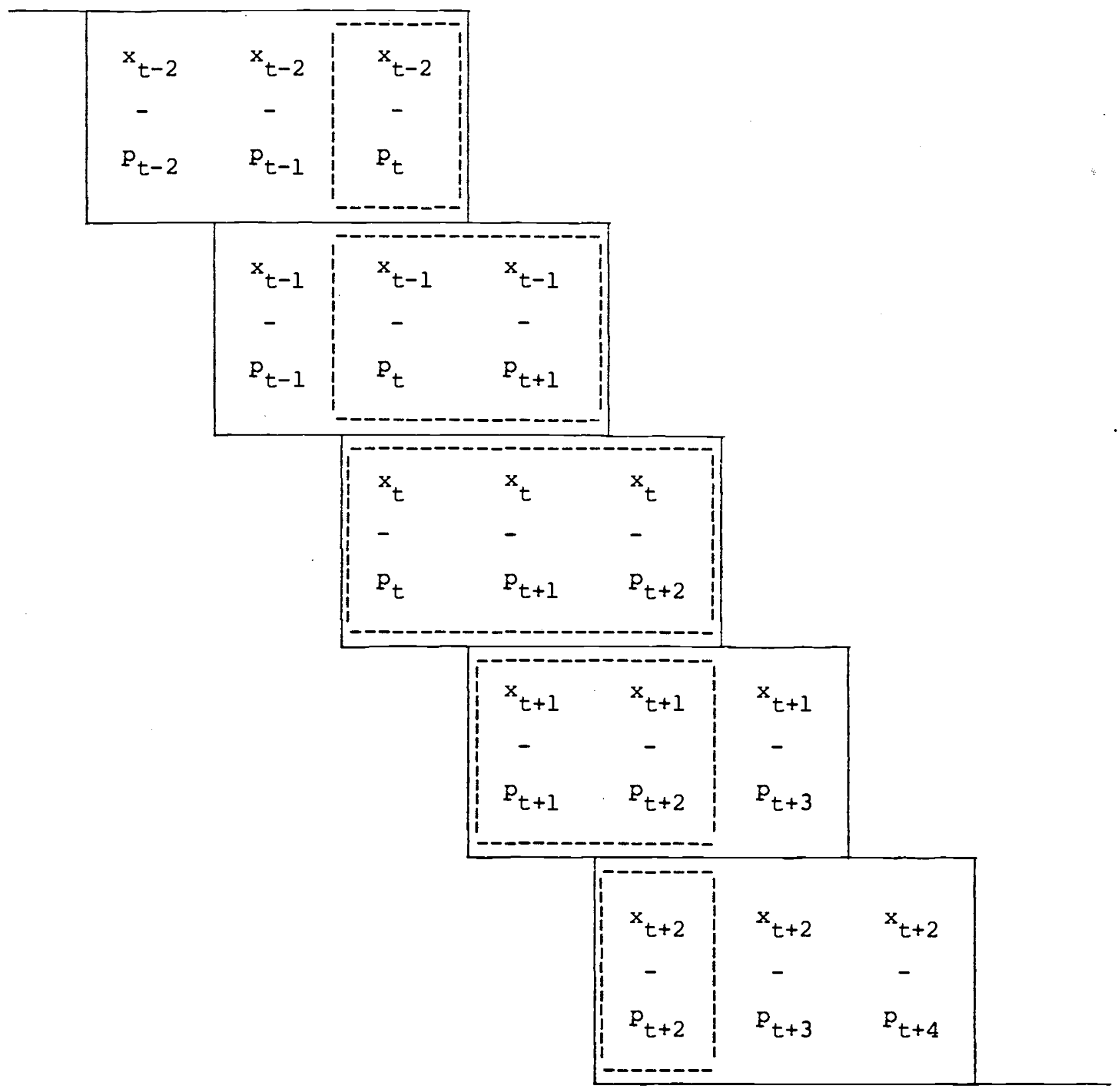

Real wage perceptions of firms and unions contracting during period $t$ in the RRW model [solid rectangles] and the RMW model [dashed rectangles]. 
$\hat{x}_{t-1 \mid t+2}-\hat{p}_{t-1 \mid t+2}$ for this expression. It can be shown (and is apparent from table 1) that

$$
\begin{aligned}
\frac{1}{N} \sum_{s=0}^{N-1} \hat{p}_{t-1 \mid t+s} & =\sum_{s=1}^{N-1} b_{s}(N-s)^{-1} \sum_{j=s}^{N-1} \hat{p}_{t-1 \mid t-s+j} \\
& +\sum_{s=1}^{N-1} b_{s}(N-s)^{-1} \sum_{j=0}^{N-1-s} \hat{p}_{t-1 \mid t+s+j}
\end{aligned}
$$

Therefore, if (5) holds, equation (7) is identically equal to equation (1), the relative money wage equation of the RMW model.

Taylor argues that firms and unions negotiating the current contract wage look at the contract wages which are set at other firms and will be in effect during their contract period. If overlapping contract wages matter because of what they imply for the real standards of living achieved by other workers and the real wage costs paid by other firms, the RRW model is clearly the appropriate one.

The solution method for the RRW model is similar to that for the RNiW model (see Taylor [1980a]), although the algebra is somewhat more involved. From (3) we see that $\hat{p}_{t-1 \mid t+k}=\frac{1}{N}{ }_{i=0}^{N-l} \hat{x}_{t-1 \mid t+k-i}$ and from (2), (3) and (4) that $\hat{y}_{t-1 \mid t+s}=-\frac{\beta}{N}{ }_{i=0}^{N-1} \hat{x}_{t-1 \mid t+s-i}$. Substitute these two expressions into (6) to obtain :

$$
\begin{aligned}
x_{t}-\frac{1}{N^{2}} \sum_{j=0}^{N-1} \sum_{i=0}^{N-1} \hat{x}_{t-1 \mid t+j-i} & =\sum_{s=1}^{N-1} b_{s}\left(x_{t-s}-\frac{1}{N^{2}} \sum_{j=0}^{N-1} \sum_{i=0}^{N-1} \hat{x}_{t-1 \mid t-s+j-i}\right) \\
& +\sum_{s=1}^{N-1} b_{s}\left(\hat{x}_{t-1 \mid t+s}-\frac{1}{N^{2}} \sum_{j=0}^{N-1} \sum_{i=0}^{N-1} \hat{x}_{t-1 \mid t+s+j-i}\right) \\
& -\frac{\gamma B}{2} \sum_{s=0}^{N-1} \sum_{i=0}^{N-1} \hat{x}_{t-1 \mid t+s-i}+\varepsilon_{t}
\end{aligned}
$$


Taking expectations of (9) as of $t-1$ and rearranging yields :

$$
\begin{aligned}
\hat{x}_{t-1 \mid t} & =\sum_{s=1}^{N-1} b_{s} \hat{x}_{t-1} \mid t-s+\sum_{s=1}^{N-1} b_{s} \hat{x}_{t-1 \mid t+s}+\frac{(1-\gamma \beta)}{N^{2}} \sum_{s=0}^{N-1} \sum_{i=0}^{N-1} \hat{x}_{t-1 \mid t+s-i} \\
& -\frac{1}{N^{2}} \sum_{s=1}^{N-1} b_{s} \sum_{j=0}^{N-1} \sum_{i=0}^{N-1} \hat{x}_{t-1}\left|t-s+j-i-\frac{1}{N^{2}} \sum_{s=1}^{N-1} b_{s} \sum_{j=0}^{N-1} \sum_{i=0}^{N-1} \hat{x}_{t-1}\right| t+s+j-i
\end{aligned}
$$

Like Taylor we use the following identity :

$$
\frac{1}{N^{2}} \sum_{s=0}^{N-1} \sum_{i=0}^{N-1} \hat{x}_{t-1 \mid t+s-i} \equiv\left(\frac{N-1}{N}\right)_{s=1}^{N-1} b_{s} \hat{x}_{t-1 \mid t-s}+\left(\frac{N-1}{N}\right) \sum_{s=1}^{N-1} b \hat{x}_{t-1} \mid t+s
$$

Equation (10) becomes :

$$
\begin{aligned}
& \hat{x}_{t-1 \mid t}\left(1-\left(\frac{1-\beta \gamma}{N}\right)\right)=\left[1+(1-\beta \gamma)\left(\frac{N-1}{N}\right)-\frac{1}{N} \sum_{s=1}^{N-1} b_{s} \hat{x}_{t-1 \mid t-s}\right. \\
& +\left[1+(1-\beta \gamma)\left(\frac{N-1}{N}\right)-\frac{1}{N}\right]_{s=1}^{N-1} \sum_{s} \hat{x}-1 \mid t+s \\
& -\left(\frac{N-1}{N}\right)_{s=1}^{N-1} \sum_{j=1}^{N-1} b_{s} b_{j} \hat{x}_{t-1 \mid t-s+j} \\
& -\left(\frac{N-1}{N}\right)_{s=1}^{N-1} \sum_{j=1}^{N-1} b_{s} b_{j} \hat{x}_{t-1} \mid t+s-j \\
& -\left(\frac{N-1}{N}\right)_{s=1}^{N-1} \sum_{j=1}^{N-1} b_{s} b_{j} \hat{x}_{t-1 \mid t-s-j} \\
& -\left(\frac{N-1}{N}\right)_{s=1}^{N-1} \sum_{j=1}^{N-1} b_{s} b_{j} \hat{x}_{t-1} \mid t+s+j
\end{aligned}
$$


Equation (12) can be written as :

$$
\sum_{s=1}^{2 N-2} B_{-s} \hat{x}_{t-1 \mid t-s}+B_{O} \hat{x}_{t-1 \mid t}+\sum_{s=1}^{2 N-2} B_{s} \hat{x} t-1 \mid t+s=0
$$

where, as we show in the appendix, the $B_{i}$ are given by :

$$
\begin{aligned}
& B_{O}=\left(3 N^{2}-N-1+3 N B Y\right) / 3 N^{2}
\end{aligned}
$$

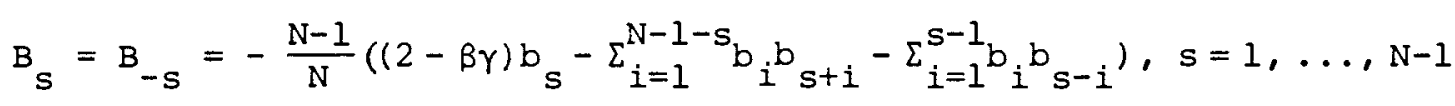

$$
\begin{aligned}
& B_{s}=B_{-s}=\frac{N-1}{N}\left(\sum_{i=s-N+1}^{N-1} b_{i s-i}^{b}\right) \quad s=N, \ldots, 2 N-2
\end{aligned}
$$

Using well-known formulae, the summations in (14b) and (14c) yield third order polynomials in $\mathrm{s}$. When the summations run from a larger to a smaller number in (14b) we take the terms to vanish.

The following points are worth noting. Firstly, ${ }_{0}$ is always positive for positive $3 y$. This can be contrasted with Taylor's model. Second, in (14c) $B_{s}$ is always positive and independent of $B \gamma$. Third, in (14b) Bs is a function of $\beta \gamma ;$ since the terms in the summation signs are all non-negative these $B_{s}$ will all change sign for some sufficient large value of BY, which will in general be different for different s.

Equation (13) can now be solved using the method presented in Taylor [1980a]. Let $L^{S} x_{t} \equiv x_{t-s}$ and define the polynomial $B(L)=\sum_{s=-(2 N-2)}^{2 N-2} B_{L} L^{s}$, where $B_{O}$ and $B_{s}=B_{-s,} s=1,2, \ldots, 2 N-2$, are as in $(14 a-c)$. Equation (13) can now be rewritten as : 


$$
B(L) \hat{x}_{t-1 \mid t}=0
$$

Because of its symmetry $B(L)$ can be factored as in (16) :

$$
B(L)=\lambda A(L) A\left(L^{-1}\right)
$$

where $\lambda$ is a normalisation constant and $A(L)$ is a polynomial of order $2 \mathrm{~N}-2$

$$
A(L)=\sum_{S=0}^{2 N-2} a_{S} L^{S}
$$

with $\alpha_{0}=1$.

A unique rational expectations solution to (15) is obtained by choosing the polynomial $A(L)$ that corresponds to the unstable roots of $B(L)$. With this choice of $A(L)$ we can divide (15) by $\lambda A\left(L^{-1}\right)$. This yields :

$$
A(L) \hat{x}_{t-1 \mid t}=0
$$

A rational expectations reduced form stochastic difference equation for $x_{t}$ ' the contract wage, is therefore given by :

$$
A(L) x_{t}=\varepsilon_{t}
$$

The $\alpha_{i}, i=0, \ldots, 2 \mathrm{~N}-2$ are obtained by solving the $2 \mathrm{~N}-1$ equations

$$
B_{s}=\lambda \sum_{u=0}^{2 N-2-s} a_{u} \alpha_{u+s} \quad s=0,1,2, \ldots, 2 N-2 .
$$


It is instructive to compare the behaviour of our RRW model with that of Taylor's RMW model, for identical values of all parameters, including contract length. This will serve to bring out the separate contributions of money illusion and "nominal inertia" due to overlapping, staggered non-contingent money wage contracts.

The reduced form solution for the contract wage in the $\mathrm{N}$-period RRA model (equations $(14 a-c),(19)$ and (20)) differs dramatically from the corresponding solution to Taylor's RMW model. The analogue to (13) in the RMW model is :

$$
\sum_{s=1}^{N-1} \bar{B}_{-s} \hat{x}_{t-1 \mid t-s}+\bar{B}_{0} \hat{x}_{t-1 \mid t}+\sum_{s=1}^{N-1} \bar{B}_{s} \hat{x}_{t-1} \mid t+s=0
$$

where

$$
\begin{aligned}
& \bar{B}_{O}=\frac{-(N+B Y)}{\bar{N}-(N-1) B Y} \\
& \bar{B}_{S}=\bar{B}_{-s}=b_{S}, \quad s=1, \ldots, N-1
\end{aligned}
$$

Using the same approach as in equations (15) - (20), we get :

$$
\bar{A}(L) x_{t}=\varepsilon_{t}
$$

Here $\bar{A}(L)$ is an N-l degree polynomial.

$$
\bar{A}(L)=\sum_{s=0}^{N-1} \bar{\alpha}_{s} L^{s}
$$

The $\bar{\alpha}_{s^{\prime}} s=1, \ldots, N-1$ are found by solving the $N$ equations 


$$
\bar{B}_{s}=\lambda \sum_{u=0}^{N-1-s} \alpha_{u} \alpha_{u+s} \quad s=0,1,2, \ldots, N-1
$$

where the $\overline{\mathrm{B}}_{\mathrm{S}}$ are defined in $(22 \mathrm{a}, \mathrm{b})$.

Thus with N-period contracts, the RRW model yields a $2 \mathrm{~N}-2$ order stochastic difference equation in the contract wage while Taylor's RWw model yields an N-1 order stochastic difference equation in the contract wage. Further differences between the two models become apparent when we consider some explicit numerical solutions for the two models. This is done in the next section. In the RRW model, as in the RMW model, the variance of output and of the price level is a function of the monetary policy parameter $B$.

3. Some numerical solutions of the relative real wage model and the relative money wage model

Consider the two-period contract case, $N=2$. Taylor's RMW model yields a first order stochastic difference equation in the contract wage

$$
\begin{aligned}
x_{t} & =-\bar{\alpha}_{1} x_{t-1}+\varepsilon_{t} \\
-\bar{\alpha}_{1} & =\frac{1+.5 \gamma \beta}{1-.5 \gamma \beta}-\sqrt{\left(\frac{1+.5 \gamma \beta}{1-.5 \gamma \beta}\right)^{2}-1}
\end{aligned}
$$

Table 2 indicates how $-\alpha_{1}$ varies as $\beta \gamma$ is increased from $0 . \quad B \gamma=0$ represents the case when the real money supply is always kept constant; equiproportional nominal money supply changes accommodate deviations of the price level from its equilibrium value. $3 \gamma<0$ would represent policies to expand the real money supply whenever the price level increases. No real solution exists for 
such policies. $B \gamma>0$ means that the nominal money supply is expancied less than proportionately (or even contracted if $B>1$ ) when the price level increases so that the real money supply declines. $-\bar{\alpha}_{1}$, the coefficient on the lagged contract wage, is positive for $O \leqslant B \gamma<\frac{\mathrm{N}}{\mathrm{N}-1}=2$ and negative for $B \gamma>\frac{N-1}{N}$. It declines monotonically as $B \gamma$ increases and approaches -1 as $B \gamma \rightarrow+\infty$.

With $N=2$, the RRW model yields a second order stochastic difference equation in the contract wage.

$$
x_{t}=-\alpha_{1} x_{t-1}-\alpha_{2} x_{t-2}+\varepsilon_{t}
$$

$\alpha_{1}$ and $\alpha_{2}$ are solved from

$$
\begin{aligned}
& \mathrm{B}_{0}=\lambda\left(1+\alpha_{1}{ }^{2}+\alpha_{2}{ }^{2}\right) \\
& \mathrm{B}_{1}=\lambda\left(\alpha_{1}+\alpha_{1} \alpha_{2}\right) \\
& \mathrm{B}_{2}=\lambda \alpha_{2}
\end{aligned}
$$

where

$$
\begin{aligned}
& B_{0}=.75+.5 \gamma \beta \\
& B_{1}=-(.5-.25 \gamma \beta) \\
& B_{2}=.125
\end{aligned}
$$


TABLE 2 : The contract wage equation in the RMW model, $\mathrm{N}=2$

$\begin{array}{lllllllllllll}B \gamma= & 0 & .1 & .2 & .3 & .4 & .5 & .6 & \ldots & 1.00 & 2.00 & +\infty \\ -\bar{\alpha}_{1}= & 1.000 & .635 & .519 & .442 & .382 & .333 & .292 & \ldots & . . & .172 & 0 & -1\end{array}$


Table 3 shows how $-\alpha_{1}$ and $-\alpha_{2}$ vary with $\beta \gamma$. The model exhibits borderline or neutral stability with $\beta \gamma=0$ and in the limit as $\beta \gamma \rightarrow \infty$. The coefficient on $x_{t-1}$ declines from 2 when $B Y=0$ to -1 when $B Y \rightarrow \infty$. The coefficient on $x_{t-2}$ starts at -1 when $\beta \gamma=0$ and rises monotonically to 0 when $\beta \gamma \rightarrow \infty$. This behaviour is clearly qualitatively different from that exhibitad by the RM model with the same contract length. It is also qualitatively different from the second order difference equation generated by the RMW model when $\mathrm{N}=3$. This case is described by equations (29) - (31) and by Table 4 .

$$
\begin{aligned}
& \mathrm{x}_{t}=-\bar{\alpha}_{1} \mathrm{x}_{t-1}-\bar{\alpha}_{2} \mathrm{x}_{t-2}+\varepsilon_{t} \\
& \overline{\mathrm{B}}_{0}=\lambda\left(1+\bar{\alpha}_{1}^{2}+\bar{\alpha}_{2}^{2}\right) \\
& \overline{\mathrm{B}}_{1}=\lambda\left(\bar{\alpha}_{1}+\bar{\alpha}_{1} \bar{\alpha}_{2}\right) \\
& \overline{\mathrm{B}}_{2}=\lambda \bar{\alpha}_{2} \\
& \overline{\mathrm{B}}_{0}=-(3+B \gamma) /(3-2 \mathrm{Br}) \\
& \overline{\mathrm{B}}_{1}=1 / 3 \\
& \overline{\mathrm{B}}_{2}=1 / 6
\end{aligned}
$$

In the RMW model with $\mathrm{N}=3$, both the coefficients on $x_{t-1}$ and on $x_{t-2}$ are positive and decline monotonically towards zero as $\mathrm{Br}$ increases from 0 to 1.5 . Both coefficients are negative for $\mathrm{Br}>1.5$ and tend asymptotically to -1 as $B \gamma>\infty$. This pattern holds generally : as $\mathrm{BY}$ increases the coefficients on all lagged values of the contract wage change sign at $B \gamma=\frac{N}{N-1}$ and tend to -1 as $B \gamma$ tends to $+\infty$. E.g., in the RMW model with $N=3$ the coefficients on $x_{t-1}$ and $x_{t-2}$ are 
TABLE 3: The contract wage equation in the RRw model, $\mathrm{N}=2$

$\begin{array}{llllllllllllllll}\beta \gamma & =0 & .1 & .2 & .3 & .4 & .5 & .6 & .7 & .8 & .9 & 1.0 & 2.0 & 10.0 & 100 . & +\infty \\ -\alpha_{1}= & 2 & .805 & .630 & .522 & .443 & .382 & .331 & .289 & .235 & .219 & .190 & 0 & -.392 & -.755 & -1 \\ -\alpha_{2}= & -1 & -.269 & -.212 & -.181 & -.161 & -.146 & -.134 & -.125 & -.117 & -.110 & -.105 & -.072 & -.025 & -.0039 & 0\end{array}$


TABLE 4: The contract waye equation in the RMW model, $\mathrm{N}=3$

$\begin{array}{llllllllllllllll}B \gamma & = & 0 & .1 & .2 & .3 & .4 & .5 & .6 & .7 & .8 & .9 & 1.0 & 1.5 & 2 & +\infty \\ -\bar{\alpha}_{1}= & .732 & .464 & .375 & .313 & .265 & .225 & .191 & .161 & .134 & .110 & .088 & 0 & -.065 & -1 \\ -\bar{\alpha}_{2}= & .268 & .188 & .158 & .135 & .117 & .101 & .087 & .074 & .063 & .052 & .042 & 0 & -.034 & -1\end{array}$


either both positive (for $B \gamma<1.5$ ) or both negative (for $2 \gamma>1.5$ ). If $8 \gamma<1.5$, a higher value of $x_{t}$ will be associated with higher money wage settlements in all subsequent periods, through the relative (money) wage effect. If policy is more restrictive $(B \gamma>1.5)$, the demand effect dominates the relative wage effect and a higher value of $x_{t}$ leads through expectations of monetary contraction and consequent excess supply of labour to lower wage settlements in subsequent periods.

In the RRW model with $\mathrm{N}=2$ the coefficient on $\mathrm{x}_{t-2}$ is always negative. The reason is that higher wage contracts formed between $t-(2 N-2)$ and $t-N$ raise the price level in the periods between $t-(N-1)$ and $t-1$. The real value of contracts negotiated between $t-(N-1)$ and $(t-1)$, which overlap with the one formed in period $t$, will therefore be lower. Via the relative real wage effect this will lower $\mathrm{x}_{t}$.

The coefficient on $x_{t-1}$ changes from positive to negative at $B Y=2$ as $B Y$ increases. A higher value of past overiapping contract wages (in general $\mathrm{x}_{t-\mathrm{N}+1}, \ldots, \mathrm{x}_{t-1}$ and with $\mathrm{N}=2$ only $\mathrm{x}_{t-1}$ ) raises $\mathrm{x}_{t}$ via the relative real wage effect. $6 /$ By raising $p_{t}$, a higher value of $x_{t-1}$ will further raise $x_{t}$ via the price expectation effect. For large enough values of $\mathrm{Br}(\mathrm{Br}>2$ if $\mathrm{N}=2)$ the positive effect of $x_{t-1}$ on $x_{t}$ can be dominated by a negative demand effect. In general, the coefficients on lagged contract wages, $x_{t-s}$ tend as. BY $\rightarrow+\infty$ to -1 for $1 \leqslant s \leqslant N-1$ and to 0 for $N \leqslant s \leqslant 2 N-2 . I /$ we expect the coefficients on $x_{t-(2 N-2)}, \ldots, x_{t-N}$ to be negative for all finite positive values of $\beta \gamma$ / and the coefficients on $x_{t-N+1}, \ldots, x_{t-1}$ to be positive for small values of $B \gamma$, and negative for large values of $B \gamma$. 


\section{Staggered wage contracts without relative wage effects}

In this section we examine the money and real wage models when Taylor's second key assumption is removed. That is, when the bargaining process does not take into account relative wages. This corresconds to the special case of the wage equations in (1) and (6) when $d_{s}=d_{-s}=0$. It enables us to separate the consequences of having relative wage effects from those of having staggered, overlapping contracts pep se.

The contract determination equation in the money wage model becomes

$$
x_{t}=\frac{\gamma}{N} \sum_{s=0}^{N-1} \hat{y}_{t-1 \mid t+s}+\varepsilon_{t}
$$

Substituting in for expected demand and taking expectations of boti sides gives

$$
\hat{x}_{t-1 \mid t}=-\frac{B \gamma}{N} \sum_{s=0}^{N-1} \hat{p}_{t-1 \mid t+s}
$$

Substituting for expected prices and using (11) we get

$$
-\frac{\hat{x}_{t-1 \mid t}}{B \gamma}=\frac{N-1}{N} \sum_{s=1}^{N-1} b_{s} \hat{x}_{t-1}\left|t-s+\frac{\hat{x}_{t-1} \mid t}{N}+\frac{N-1}{N} \sum_{s=1}^{N-1} b_{s} \hat{x}_{t-1}\right| t+s
$$

or rearranging

$$
-\left(\frac{N+B \gamma}{B \gamma(N-1)}\right) \hat{x}_{t-1}\left|t=\sum_{s=1}^{N-1} b_{s} \hat{x}_{t-1}\right| t-s+\sum_{s=1}^{N-1} b_{s} \hat{x}_{t-1} \mid t+s
$$

We can solve equation (34) exactly as before. Table 5 presents the lag weights on the resulting stochastic difference equation for $\mathrm{N}=2,3$ and various values of $B \gamma$. 
Table 5 The Contract Wage Equation in the Moncy wage Model Without Relative Wage Effects

\begin{tabular}{lllllllllll} 
Br $=$ & 0 & 0.1 & 0.2 & 0.3 & 0.4 & 0.5 & 0.6 & 1.0 & 10 & $\infty$ \\
\hline
\end{tabular}

\begin{tabular}{|c|c|c|c|c|c|c|c|c|c|c|c|c|}
\hline $\mathrm{N}=2$ & $-\bar{\alpha}_{1}$ & $=$ & 0 & -.024 & -.046 & -.065 & -.084 & -.101 & -.116 & -.172 & -.537 & -1 \\
\hline $\mathrm{N}=3$ & $-\bar{\alpha}_{1}$ & $=$ & 0 & -.022 & -.041 & -.058 & -.077 & -.092 & -.106 & -.159 & -.533 & -1 \\
\hline & $-\bar{\alpha}_{2}$ & $=$ & 0 & -.011 & -.021 & -.030 & -.040 & -.048 & -.056 & -.086 & -.363 & -1 \\
\hline
\end{tabular}


In the money wage model without relative wage effects, less accormodating policy (that is, larger values of $\mathrm{pr}$ ) imereases the dependence of current wages on past wages, as reflected in the larger absolute values of the (negative) lag coefficients. The behaviour of Taylor's RH model is similar to that of the money wage model without relative wage effects, when tine cemand effect dominates, that is for large values of $B \gamma$. For small values of $3 y$ the relative wage effect dominates the demand effect in Taylor's moziel and the dependence of current wages on past wages diminishes as $3 \gamma$ increases from zero to $\mathrm{N}(\mathrm{N}-1)^{-1}$. This behaviour can be seen clearly in Tables 2) 4) and 5).

In the real wage model we can similarly disentangle the demand effect from the relative real wage effect and the price expectation effect. In equation (6) we set $d_{s}=d_{-s}=0$, which gives

$$
x_{t}-\frac{1}{N} \sum_{s=0}^{N-1} \hat{p}_{t-1 \mid t+s}=\frac{Y}{N} \sum_{s=0}^{N-1} \hat{y}_{t-1 \mid t+s}+\varepsilon_{t}
$$

Substituting for expected demand we have

$$
x_{t}-\frac{1}{N} \sum_{s=0}^{N-1} \hat{p}_{t-1 \mid t+s}=-\frac{\beta \gamma}{N} \sum_{s=0}^{N-1} \hat{p}_{t-1 \mid t+s}+\varepsilon_{t} .
$$

Now substituting money wages for prices and taking expectations of both sides gives

$$
\hat{x}_{t}=\frac{1-B Y}{N^{2}} \sum_{s=0}^{N-1} \sum_{i=0}^{N-1} \hat{x}_{t-1 \mid t+s-i},
$$

which upon applying (11) and rearranging gives

$$
\frac{N+(N-1)^{-1} N E \gamma}{N-N B \gamma} \hat{x}_{t-1 \mid t}=\sum_{s=1}^{N-1} b_{s} \hat{x}_{t-1 \mid t-s}+\sum_{s=1}^{N-1} b_{s} \hat{x}_{t-1} \mid t+s
$$


Comparing this with the equivalent expression in the R:IW model $(21,22 a, 220)$ we can see that the equations are identical when $\mathrm{Br}$ in this model takes $a$ value $(\mathrm{N}-\mathrm{I}) \mathrm{N}^{-1}$ times that in the RHW model. This means that policy is iv (N-I) ${ }^{-1}$ times more effective in this model than it is in the RMW nodel, but that otherwise they are identical.

The only way to distinguish empirically between the money vage mociel with relative wage effects and the real wage model without relative wage effects is by knowing $B \gamma$ and $N$ a priori. Otherwise the two models are observationally equivalent.

It has already been snown (Phelps and Taylor [1977], Fischer [1977]) that in order to obtain the conclusion that known monetary policy rules affect real output, it is sufficient to have multi-period non-contingent money wage (or price) contracts. It is neither essential to have relative wage effects nor for contracts to be staggered. Different policy rules will have different effects whenever the money stock can be made to respond to new information bejore all private agents can revise wage contracts. To include such features as relative wage effects and staggerea contracts may of course be desirable for its cwin sake because it captures an essential feature of reality. 
5. Some empirical implications of the relative real wage rodel

The RRW model and the RMN model have some directly testable implications even if the contract wage cannot be observed. From the price level equation. (3) we see that, if $\mathrm{N}=2$, the price equation of the RM model is the ARIMA $(1,1)$ process

$$
\begin{aligned}
& p_{t}=-\bar{\alpha}_{1} p_{t-1}+\frac{1}{2} \varepsilon_{t}+\frac{1}{2} \varepsilon_{t-1} \\
& \text { with }-1 \leqslant-\bar{\alpha}_{1} \leqslant 1 .
\end{aligned}
$$

With $N=2$, the price equation of the $\operatorname{RRW}$ model is the ARIMA $(2,2)$ process

$$
\begin{aligned}
& p_{t}=-\alpha_{1} p_{t-1}-\alpha_{2} p_{t-2}+1 / 3 \varepsilon_{t}+1 / 3 \varepsilon_{t-1}+1 / 3 \varepsilon_{t-2} \\
& \text { with }-1 \leq-\alpha_{1} \leq 2 \text { and }-1 \leq-\alpha_{2} \leq 0 .
\end{aligned}
$$

The price equation for the RMW model with $N=3$ is also an $\operatorname{ARIMA}(2,2)$ process :

$$
\begin{aligned}
& p_{t}=-\bar{\alpha}_{1} p_{t-1}-\bar{\alpha}_{2} p_{t-2}+1 / 3 \varepsilon_{t}+1 / 3 \varepsilon_{t-1}+1 / 3 \varepsilon_{t-2} \\
& \text { with } .732 \geqslant-\bar{\alpha}_{1} \geqslant-1 ; .268 \geqslant-\bar{\alpha}_{2} \geqslant-1 ;\left|\bar{\alpha}_{1}\right|>\left|\bar{\alpha}_{2}\right| . \\
& \operatorname{sign}\left(-\bar{\alpha}_{1}\right)=\operatorname{sign}\left(-\bar{\alpha}_{2}\right) .
\end{aligned}
$$

Given a priori knowledge of $\mathrm{N}$, we can test the RRW hypothesis that the price data foliow an ARIMA $(2 \mathrm{~N}-2,2 \mathrm{~N}-2)$ process against the RMW hypothesis test that the price data follow an ARIMA (N-1, N-1) process. It is much less straightforward to include in these tests the inequality constraints on the $\alpha_{i}$ and $\bar{\alpha}_{i}$ coefficients shown for $N=2$ in (38b) and (38c). Alternatively, without prior knowledge of $N$, we can select the best-fitting ARIMA (i, i) process $(i \geqslant 1)$ for the price data. If $i=1$ and the other restrictions of (38a) are 
not rejected by the data, the RMr model is corsistent with the data and the RRW model is not. If $i>1$, non-rested hypothesis tests are in generai required to discriminate between the RRi and the RMW model on the basis of inequality constraints such as those given in (38b) and (38c). However, finding a positive coefficient for the longest lag on $p_{t}$ is alvays inconsistent with the RRW rodel and finding coefficients with dirferent signs is alvays inconsistent with the par rodel. Taylor, in his empirical rork on the kn model (see specifically Taylor [1000b] but also Taylor [1979b]) uses the $\mathrm{N}=2$ version of the nodel, which yielas the ARIM $(1,1)$ process of equation (38a). This equation could never have been generated by the RRW mocei which alvays yields at least an ARIMA $(2,2)$ grocess for tine general price level. In the most direct test of the RM model (Taylor [1930b]) with $\mathrm{N}=2$, it is found necessary to let the rancom disturbances $\varepsilon_{t}$ and $v_{t}$ follow a first order HA process. It is, in princiole, alvays undesirable to have to attribute systematic explanatory power to the disturbance terms of a model. In this case, however, one mignt go Iurther and argue that equation (38a) witn an MA (1) process for $\varepsilon_{t}$ may well be a misspecification that should be tested against (38b), the RRW model with $N=2$, or against (38c), the RMW model with $N=3$, both with i.i.d. $\varepsilon_{t}$. To perform these and other empirical tests of the two models is a priority for future research. 


\section{Conclusions}

The RRW model we developed as an alternative to Taylor's R'T model differs from the latter in one important respect. Taylor's $2 \mathrm{WW}$ model views the money wage decision of firms and unions contracting in a given period as influenced by the money wage rates set (or expected to be set) by other firms and unions that will be in effect during their own contract period. The RRW model views current wage bargainers as attempting to achieve a real wage target over the life of their contract that is influenced by the real wages achieved or expected to be achieved by those other wage bargainers with whose contract periods there is some degree of overlap.

Quite significant differences in behaviour are exhibited in otherwise identical RRW and RMW models. With $\mathrm{N}$-period contracts, the RRW model yields a 2N-2 order stochastic difference equation for the contract wage and an ARIMA $(2 N-2,2:-2)$ process for the general price level. The corresponding RMW model yields an $\because-1$ order stochastic difference equation for the contract wage and an ARIMA $(\mathrm{N}-1, \mathrm{~N}-1)$ process for the general price level. With the RMW model the coefficients on lagged contract wages in the contract wage equation always have a common sign and decline both in the order of the lag and with the degree of non-accommodation of monetary policy. The lag coefficients in the RRW model will generally have mixed signs. It was also shown that Taylor's RMW model is observationally equivalent to a real wage model without relative wage effects.

What is perhaps the major qualitative conclusion of Taylor's RMW model is not affected, however. This is that rational expectations combined with nominal inertia due, e.g. to overlapping, staggered,non-contingent money wage contracts leaves scope for known contingent monetary policy rules to influence such real variables as the variance of output. 
FOOTNOTES

1. The simplest interpretation of (2) is that of the quantity theory equation of exchange with the (logarithm of the) income velocity of circulation represented by a white noise disturbance term $v_{t}$.

2. In Taylor's PMW model, as in the RRW model specified below, output rould be affected by lagged monetary feeaback as well (e.g. $\left.m_{t}=\delta p_{t-1}\right)$. Unless the policy rule is "symmetric in time" (e.g. $\left.\mathrm{m}_{t}=\delta p_{t-1}+(1-\beta) F_{t}+\delta \hat{p}_{t-l_{j} t+1}\right)$ the simple algebraic structure of the RMW model and the RRi n:odel is lost because the polynomial equation in the expected contract wage is no ionger symmetric.

3. The non-contingent nature of these contracts means that the $\mathrm{N}$-period wage contract negotiated in period $t$ does not make the wages paid unaer the contract in periods $t+1, \ldots, t+N-1$ contingent on information (on future contract wages, future prices and future excess demanas) that may become available during the life of the contract. If a multi-period contract made the money wages paid over the life of the contract contingent on future information, it would be equivalent to a sequence of single-period contracts.

4. Substituting for $b_{s}$ in equation (8) gives

$$
(N-1) \sum_{s=0}^{N-1} \hat{p}_{t-1 \mid t+s}=\sum_{s=1}^{N-1}\left(\Sigma_{j=s}^{N-1} \hat{p}_{t-1 \mid t-s+j}+\Sigma_{j=0}^{N-1-s} \hat{p}_{t-1 \mid t+s+j}\right)
$$




$$
\begin{aligned}
& \sum_{j=s}^{N-1} \hat{p}_{t-1 \mid t-s+j}=\sum_{j=0}^{N-1-s} \hat{p}_{t-1 \mid t+j} \\
& \sum_{j=0}^{N-1-s} \hat{p}_{t-1 \mid t+s+j}=\sum \sum_{j=s}^{N-1} \hat{p}_{t-1 \mid t+j^{\prime}}
\end{aligned}
$$

and

$$
\begin{aligned}
& \sum_{s=1}^{N-1} \sum_{j=0}^{N-1-s} \hat{p}_{t-1 \mid t+j}=\sum_{s=0}^{N-2}(N-1-s) \hat{p}_{t-1 \mid t+s} \\
& \sum_{s=1}^{N-1} \sum_{j=s}^{N-1} \hat{p}_{t-1 \mid t+j}=\sum_{s=1}^{N-1} s \hat{p}_{t-1 \mid t+s^{\prime}}
\end{aligned}
$$

the identity is easily established.

5. From (22a) $\bar{B}_{O}$ goes to infinity as $B \gamma$ goes to $\frac{N}{N-1}$. Diviaing (21) by $\bar{B}_{O}$ and taking the limit as $B \gamma \rightarrow \frac{N}{N-1}$ yields $\hat{x}_{t-1 / t}=0$. Therefore $x_{t}=\varepsilon_{t}$ is a solution.

Again from $(22 a) \bar{B}_{O}$ goes to $(N-1)^{-1}$ as $B \gamma$ goes to to. By direct substitution it can be checked that $\alpha_{s}=1, s=1, \ldots, N-1$, satisfies (25). (Note that $\lambda=[(N-1) N]^{-1}$ ).

6. The increase in the period $t-1$ real wage will (aue to the dependence of prices on wages) be less than the increase in the period $t-1$ nominal wage.

7. From equations $(14 a, b, c)$ we get $\underset{B \gamma \rightarrow \infty}{\lim _{B}\left(\frac{B}{B_{O}}\right)}=\frac{N-s}{N}$ for $1 \leq s \leq N-1$ and $\lim _{B \gamma \rightarrow \infty}\left(\frac{B}{B_{O}}\right)=0$ for $N \leqslant s \leqslant 2 N-2$. Dividing (20) by $B_{O}$ we get

$$
\frac{B_{s}}{B_{O}}=\frac{\sum_{i=0}^{2 N-2-s} \alpha_{u}^{\alpha} u+s}{2 N-2} 2, s=1, \ldots, 2 N-2
$$


Taking the limit as $B \gamma \rightarrow \infty$ this reduces to

$$
\begin{aligned}
& \frac{N-s}{N}=\frac{\sum_{i=0}^{2 N-2-s} \alpha_{u}^{\alpha} u+s}{2 N-2 \alpha_{i}^{2}} \quad s=1, \ldots, N-1 \\
& 0=\frac{\sum_{i=0}^{2 N-2-s} \alpha_{u} \alpha_{u+s}}{2 N-2{ }_{i=0}^{2} \alpha_{i}} \quad s=N, \ldots, 2 N-2
\end{aligned}
$$

These two sets of equations are satisfied by

$$
\alpha_{i}=\left\{\begin{array}{lll}
1, & i=1, \ldots, N-1 \\
0 & i=N, \ldots, 2 N-2
\end{array}\right.
$$

8. It is obvious that thecoefficient on $\hat{x}_{t-2 N+2}$ is always negative for finite positive $B \gamma$. 
Fischer, Stanley, "Long-term Contracts, Rational Expectations, and the Optimal Money Supply Rule", Journal of Political Economy, 85, Feb. 1977, pp. 191-206.

Phelps, Edmund S. and Taylor, John B., "Stabilizing Powers of Monetary Policy under Rational Expectations", Journal of Political Ecoromy, 85, Feb. 1977, pp. 163-190.

Taylor, John B. [1979a], "Staggered Wage Setting in a Macro World", Areerican Economic Review, May, pp. 108-113.

[1979b], "Estimation and Control of a Macroeconomic Mcdel witin Rational Expectations", Econometrica, 47, September, pp, 1267-86.

[1980a], "Aggregate Dynamics and Staggered Contracts", Journal of Political Economy, 88, February, pp. 1-23.

[1980b], "Output and Price Stability", Journal of Econonic Dynamics and Control, 2, February, pp. 109-132. 


\section{APPENDIX}

In this appendix we show that equation (13), with the $B_{j}$ as given in $(14 a, b, c)$, is equivalent to equation (12). Except for rearrangement we only have to determine the coefficients of $\hat{x}_{t-1 \mid t+r}, \hat{x}_{t-1 \mid t-r}$, for $r=0, \ldots, 2 N-2$, in the bilinear forms on the right hand side of equation (12). There are four such bilinear forms but by symmetry we need only consider two cases. The problem, then, is to find $K_{x}$ and $M_{x}$ such that (A1) and (A2) hold:

$$
\begin{aligned}
\left(\Sigma_{s=1}^{N-1} \Sigma_{j=1}^{N-1} b_{s} b_{j} \hat{x}_{t-1 \mid t-s+j}\right. & \left.+\Sigma_{s=1}^{N-1} \Sigma_{j=1}^{N-1} b_{s} b_{j} \hat{x}_{t-1 \mid t+s-j}=\right) \\
2 \Sigma_{s=1}^{N-1}{ }_{j=1}^{N-1} b_{s} b_{j} \hat{x}_{t-1 \mid t-s+j} & =\Sigma_{r=1}^{N-2} k_{r} \hat{x}_{t-1} \mid t+r \\
& +k_{0} \hat{x}_{t-1} \mid t \\
& +\Sigma_{r=1}^{N-2} k_{r} \hat{x}_{t-1} \mid t-r \\
\sum_{s=1}^{N-1} \Sigma_{j=1}^{N-1} b_{s} b_{j} \hat{x}_{t-1 \mid t+s+j} & =\Sigma_{r=2}^{2 N-2} \hat{x}_{t-1 \mid t+x .} .
\end{aligned}
$$

Consider (Al) first. In this equation we have

$$
j=s+r
$$

The fact that $j$ takes values only between $l$ and $N-1$ means that, for $r \geq 0, s$ is constrained to taking the values between $l$ and $N-1-r$. For each $s$ in this domain we have a corresponding $j$ (given by (A3)) and a value for $b_{j} b_{s}$, the sum of all these (multiplied by 2) is the coefficient of $\hat{x}_{t-1 \mid t+r}$. Hence

$$
k_{-r}=k_{r}=\Sigma_{i=1}^{N-1-r} b_{i} b_{r+i}, \quad r=0, \ldots, N-2
$$


Because of the linearity of $b_{k}$ in $k$ we can easily carry out the summation in (A4). Substituting in for $b_{i}$ and $b_{r+i}(A 4)$ becomes :

$$
K_{-r}=K_{r}=\Sigma_{i=1}^{N-1-r} \frac{(N-i)(N-r-i)}{\left[N(N-1) j^{2}\right.}=\Sigma_{i=1}^{N-1-r} \frac{N(N-r)-(2 N-r) i+i^{2}}{[N(N-1)]^{2}}
$$

Now using the following identities :

$$
\begin{aligned}
\sum_{i=1}^{N-1-r} N(N-r) & =(N-1-r) N(N-r) \\
\sum_{i=1}^{N-1-r}(r-2 N) i & =\frac{1}{2}(N-1-r)(N-r)(r-2 N) \\
\sum_{i=1}^{N-1-r} i^{2} & =1 / 6(N-1-r)(N-r)(2 N-2 r-1)
\end{aligned}
$$

we have

$$
K_{-r}=K_{r}=\frac{(N-1-r)(N-r)(2 N+r-1)}{6[N(N-1)]^{2}} \quad r=0, \ldots, N-2 .
$$

And in particular,

$$
K_{0}=\frac{2 N-1}{6 N(N-1)}
$$

Now we deal with (A2). Proceeding as before, $M_{X}$ is the sum of the series $b_{S} b_{j}$ for which

$$
s+j=r,
$$

and both $s$ and $j$ lie between 1 and $\mathrm{N}-1$. Hence,

$$
\begin{array}{ll}
1 \leqslant j \leqslant N-1 & \text { and } \\
1 \leqslant s=r-j \leqslant N-1 & \Rightarrow r-N+1 \leqslant j \leqslant r-1
\end{array}
$$


The upper and lower bounds on $j$ depend on the value of $r$. There are two cases

$2 \leqslant r \leqslant N-1$, in which case $j$ lies between 1 and $r-1$

$$
2 N-2 \geqslant r \geqslant N \quad \text {, in which case } j \text { lies between } r-N+1 \text { and } N-1
$$

Therefore,

$$
\begin{array}{ll}
M_{-r}=M_{r}=\sum_{j=1}^{r-1} b_{j} b_{r-j} & r=2, \ldots, N-1 \\
M_{-r}=M_{r}=\sum_{j=r-N+1}^{N-1} b_{j} b_{r-j} & r=N, \ldots, 2 N-2
\end{array}
$$

We can now write equation (12) as

$$
\begin{aligned}
& \quad \frac{N-1}{N} \Sigma_{s=N}^{2 N-2} M_{-s} \hat{x}_{t-1 \mid t-s}-\frac{N-1}{N} \sum_{s=1}^{N-1}\left((2-\beta \gamma) b_{s}+K_{-s}+M_{-s}\right) \hat{x}_{t-1} \mid t-s \\
& +\left(1-\frac{(1-\beta \gamma)}{N}+\frac{N-1}{N} K_{0}\right) \hat{x}_{t-1}\left|t-\frac{N-1}{N} \sum_{s=1}^{N-1}\left((2-\beta \gamma) b_{s}+K_{s}+M_{s}\right) \hat{x}_{t-1}\right| t+s \\
& +\frac{N-1}{N} \Sigma_{s=N}^{2 N-2} M_{s} \hat{x}_{t-1} \mid t+s=0
\end{aligned}
$$

Here, as in the text, we adopt the convention that, when a summation runs from a smaller to a larger number, the term vanishes. Substituting (A5, ...,9) in equation (AlO) and comparing with equation (13) gives $(14 a, \ldots, c)$. 